a striking improvement in patients with peptic ulceration follows their employment (Matts and Swan, 1964). An antisecretory agent (poldine) is recommended in treatment and shown to be of value (Douthwaite, 1958), although later work shows it to have no effect in reducing the gastric acidity in duodenal-ulcer patients taking a bland diet (Lennard-Jones, 1961).

Other interesting therapeutic agents are carbenoxolone disodium salt (Biogastrone) and stilboestrol. Both have been subjected to carefully controlled clinical trials in pepsin ulceration and have been clearly shown to be valuable (Truelove, 1960 ; Doll, Hill, Hutton, and Underwood, 1962), but the mode of action of each is not clear.

We would like to put forward the possibility of a local coating action as an explanation for the efficacy of bismuth aluminate in peptic ulceration, and consider that this might fit into current views on the causation of peptic ulcer by increasing the tissue-resistance component of the equation acid-pepsin versus the defensive powers of the mucosa. Certainly our in vivo gastric studies have thrown much doubt on whether the normal therapeutic dosage of either magnesium trisilicate or bismuth aluminate has any lasting or significant effect on the contents of the lumen of the stomach. In spite of this we have demonstrated considerable therapeutic benefit from their use.

\section{Summary}

A double-blind controlled trial has been carried out comparing bismuth aluminate with magnesium trisilicate in patients with peptic ulceration. The results were analysed by restricted sequential analysis and a clear clinical advantage to bismuth aluminate was seen. In vivo, gastric analysis of the patients in the trial shows that neither agent has a significant effect on gastric $p \mathrm{H}$ or pepsin activity in the lumen of the stomach. The possibility of a local coating effect of bismuth is suggested as an explanation of its clinical efficacy.

We would like to thank Drs. J. V. S. A. Davies, P. A. Thorn, and W. A. Hudson for allowing us to study patients under their care; Dr. G. Walters for his advice and co-operation; Mr. F. Leonard, of M.C.P. Pure Drugs, for his assistance and supplies of bismuth aluminate (Bislumina); and the sisters and nurses of the Royal Hospital for their co-operation.

\section{REFERENCES}

Armitage, P. (1954). Quart. F. Med., 23, 255.

Bateson, P. R. (1954). Med. ill. (Lond.), 8, 370.

- (1958). f. Pharm. Pharmacol., 10, 123.

Doll, R., Friedlander, P., and Pygott, F. (1956). Lancet, 1, 5.

- Hill, I. D., Hutton, C., and Underwood, D. J. (1962). Ibid., 2, 793.

- Price, A. V., Pygott, F., and Sanderson, P. H. (1956). Ibid., 1, 70.

Douthwaite, A. H. (1958). Proc. roy. Soc. Med., 51, 1063.

Dragstedt, L. R. (1962). Ann. N.Y. Acad. Sci., 99, 190.

Hollander, F. (1962). Ibid., 99, 4.

Hunt, J. N. (1948). Biochem. F., 42, 104.

Jones, F. Avery (1964). Brit. med. F., 1, 754.

Kay, A. W. (1964). Ibid., 1, 754.

Lancet, 1962, 2, 1313.

Lennard-Jones, J. E. (1961). Brit. med. F., 1, 1071.

Matts, S. G. F. (1960). Lancet, 1, 517.

- and Swan, C. H. J. (1964). Proceedings of International Congress of Gastro-Enterology, Brussels.

of Gastro-Enterology, Brussels.

Nicol, B. M. (1939). Lancet, 2, 881.
Pygott, F. (1954). Ibid., 1, 1314.

Pygott, F. (1954). Ibid., 1, 1314.

Schaub, K. (1963). Pharm. Acta Helv., 38, 15

Snell, E. S., and Armitage, P. (1957). Lancet, 1, 860.

Spira, J. J.' (1956). Gastro-Duodenal Ulcer. Butterworth, London.

(1964). Lancet, 1, 613.

Stephens, R. L. (1953). F. Pharm. Pharmacol., 5, 704.

Sun, D. C. H. (1962). Ann. N.Y. Acad. Sci., 99, 104.

Truelove, S. C. (1960). Brit. med 7., 2, 559.

Watkinson, G. (1958). Ibid., 2, 1077.

\title{
Mass Miniature Radiography in Detection of Heart Disease
}

\author{
M. BARRY,* M.D., B.SC., M.R.C.P.I. ; H. A. FLEMING, $\dagger$ M.D., M.R.C.P.
}

Brit. med. F., 1965, 1, 756-759

In recent years advances in the diagnosis and surgical treatment of congenital and rheumatic heart disease have given greater importance to their early recognition. In addition, prophylactic treatment can be given against recurrences of rheumatic fever or the occurrence of bacterial endocarditis. Where the cardiac abnormality is an insignificant one an early authoritative explanation of this may avoid many unnecessary restrictions and possible cardiac neurosis.

Many different screening techniques for early diagnosis of heart disease have been pioneered, particularly in the United States of America. Mass miniature radiography has been used in many centres to help in the detection of heart disease, and is usually run in conjunction with a survey for lung diseases. The use and value of this method has been reported by West (1946), Flancher (1948), Bostock and Morris (1952), Porte (1952), and Schwartz and Berman (1952).

Maclean and Rogen (1949) carried out a survey in Glasgow using $35 \mathrm{~mm}$. chest $x$-ray films. They had the advantage of prior knowledge of either a history of rheumatic fever or of heart disease. Of 34,918 persons $x$-rayed, 1,703 were recalled and 220 of these were found to have heart disease. The know-

* Consultant Physician, Ipswich Chest Clinic.

t Consultant Cardiologist, East Anglian Regional Hospital Board and Addenbrooke's Hospital, Cambridge. ledge of the history may account for the large number of recalls, but in some cases the history was found to be incorrect.

Mathisen et al. (1950), using 5 by 4 -in. ( 12.5 by $10-\mathrm{cm}$.) chest $x$-ray films, reported on the detection of heart disease in a selected group-namely, patients referred by their physicians with suspected thoracic disease.

Selzer et al. (1951) in their screening techniques used 35-mm. films. Suspected cases were recalled for fluoroscopic examination. If the cardiac outline was still thought to be abnormal these patients were recalled for investigation. This duplication seems unnecessary.

Morton et al. (1959a) used 70-mm. chest $x$-ray films, lead $\mathrm{V}_{3} \mathrm{R}$ of the electrocardiogram, and physical examination by a team of 13 cardiologists. They discovered 33 cases of heart disease among 6,300 children examined and all but seven of these were congenital heart lesions. The method was laborious and expensive and would seem impracticable on a large scale. Morton et al. (1959b) compared three methods of screening schoolchildren: the single lead $\mathrm{V}_{3} \mathrm{R}$ electrocardiogram, a miniature chest $x$-ray film, and a limited physical examination. Their conclusions were that none of these methods alone was satisfactory and that the minimum basic examination still consisted of a full physical examination, chest $x$-ray film, and electrocardiogram. 
Smith et al. (1959) and Miller et al. (1962) used tape-recorded heart sounds for discovering heart disease. These recordings were then analysed by a team of cardiologists. This method appears liable to many fallacies. The frequency of innocent systolic murmurs, especially in children, would lead to a large number of normal recalls. This is borne out by the experience of Morton et al. (1959a), who found that one-third of the children they examined had innocent systolic murmurs.

The majority of these reports have failed to assess the severity of the lesions discovered, to detail confirmatory investigations, or to state whether corrective surgery had been carried out.

\section{Material and Method}

In 1958 a chest $x$-ray survey of the rural population of East Suffolk was started, its main object being to discover new cases of pulmonary tuberculosis and other chest diseases. The propaganda and administration were organized at parish level. The Parish Council and voluntary workers in the area (W.V.S., Women's Institutes, etc.) were approached and asked to cooperate. House-to-house canvassing was done and the propaganda was based on the help this survey could give to the eradication of pulmonary tuberculosis in their parish.

After the survey had been in action for six months it was decided to investigate the value of using miniature chest $x$-ray films for the detection of heart disease. This was done independently of the main survey and was not mentioned in the propaganda carried out locally by the voluntary bodies. Each miniature film was scrutinized by one observer (M. B.) solely from a cardiological point of view, ignoring any chest lesions not affecting the heart or great vessels. In this exercise nothing was known of the persons $x$-rayed except their name, age, sex, and the name of their general practitioner. The community $x$-rayed was rural apart from one urban area of 25,000. Most of the villages had populations between 200 and 800 . In the beginning the whole population of each village, including schoolchildren, were $x$-rayed. In two parishes a target of $100 \%$ was achieved while in the remaining parishes the figures ranged from 70 to $90 \%$ with a few exceptions. Later, after the report of the Adrian Committee (1959) on radiation hazards, children under 16 years were excluded. Though the discovery of congenital and valvular heart disease was the prime object of this exercise other forms of heart disease were also found.

The procedure adopted in detecting heart disease in this exercise was as follows: (1) The $70-\mathrm{mm}$. $x$-ray films were examined by one observer (M.B.) ; (2) when an abnormality was found the patient was recalled: a full history was taken and a physical examination carried out, a 17 by 14-in. (43 by $35.5-\mathrm{cm}$.) chest $x$-ray film was taken at $6 \mathrm{ft}$. $(1.8 \mathrm{~m}$.) and a 12-lead electrocardiogram was obtained; and (3) any patients with abnormal physical findings were referred to the cardiologist.

When the patients were recalled the abnormality detected in the $70-\mathrm{mm}$. $x$-ray film was described to the practitioner and he was told of the possible explanations of this abnormality along the following lines: (1) that it was due to bad positioning; (2) that it was due to skeletal deformity; (3) combination of bad positioning and skeletal deformity ; (4) presence of congenital or acquired heart disease.

The patients recalled were told to consult their doctor before reporting to the clinic. This was done routinely, and the family doctor, having had the above information, was in a position to offer an explanation to his patients. The general practitioners were kept informed at all stages of the presumed diagnosis, of the final diagnosis, and of any investigations or surgical treatment advised.

\section{Results}

The available population during this exercise was 121,815 . The number of persons $x$-rayed was 83,129 (including 17,620 children), and this represents $68.24 \%$ of the available population. The results of the exercise are shown in Table I. Table II, for comparison, shows the result of the main survey on pulmonary tuberculosis and other chest diseases discovered in the same population.

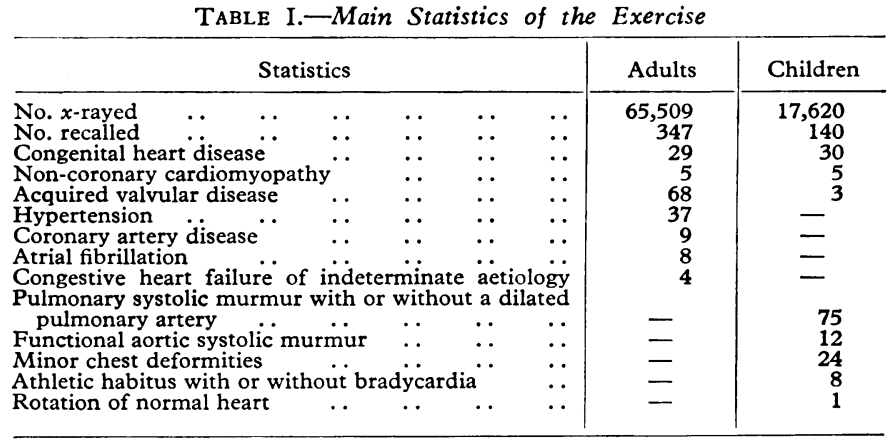

TABLE II.-Chest Diseases Discovered in the 83,129 Persons X-rayed

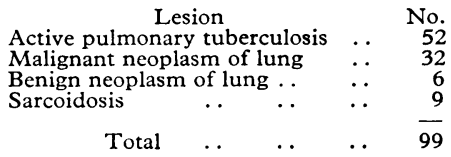

The children were studied more completely than the adults in an effort to discover factors which influenced the $x$-ray appearances and physical findings. A list of the less significant findings in children can be found in part of Table I. The ages of the children with heart disease ranged from 8 to 16 years. Two cases of treated ductus arteriosus, two cases of Fallott's tetralogy with Blalock's operation, and two cases of idiopathic steatorrhoea (large hearts because of anaemia) were also discovered. The cases of idiopathic steatorrhoea were previously unknown. The lesions discovered in the children are set out in Table III.

TABLE III.-Children-Heart Disease. (Number of Children X-rayed, $17,620$. Defect rats per $1,000,2.15)$

\begin{tabular}{|c|c|c|c|c|c|c|}
\hline Defect & $\dot{\mathrm{Z}}$ & 离 & 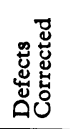 & 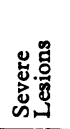 & 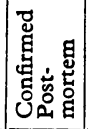 & 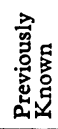 \\
\hline $\begin{array}{l}\text { Atrial septal defect } \\
\text { Atrial septal defect with pulmonary }\end{array}$ & 9 & 8 & 7 & 9 & - & 1 \\
\hline $\begin{array}{l}\text { stenosis } \\
\text { Atrial septal defect with coarctation }\end{array}$ & 1 & 1 & - & 1 & - & 1 \\
\hline $\begin{array}{l}\text { of aorta } \\
\text { Total anomalous pulmonary venous }\end{array}$ & 1 & 1 & 1 & 1 & - & - \\
\hline $\begin{array}{l}\text { drainage } \ldots \\
\text { Persistent ductus arteriosus } \ldots \\
\text { Persistent ductus arteriosus }\end{array}$ & $\begin{array}{l}1 \\
3\end{array}$ & $\begin{array}{l}1 \\
3\end{array}$ & $\begin{array}{l}1 \\
3\end{array}$ & 1 & $\overline{-}$ & $\begin{array}{l}1 \\
1\end{array}$ \\
\hline 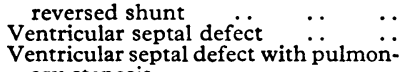 & $\begin{array}{l}1 \\
3\end{array}$ & $\begin{array}{l}1 \\
2\end{array}$ & $\overline{1}$ & 1 & $\overline{-}$ & - \\
\hline $\begin{array}{l}\text { ary stenosis ... } \\
\text { Ventricular septal defect (Eisenmenger }\end{array}$ & 1 & - & - & 1 & - & 1 \\
\hline $\begin{array}{cccc}\text { type) } & \cdots & \\
\text { Pulmonary stenosis } & \cdots & \cdots & \cdots\end{array}$ & $\frac{1}{6}$ & $\begin{array}{l}1 \\
5\end{array}$ & $\overline{-}$ & 1 & - & $\overline{-}$ \\
\hline Primary pulmonary hypertension $\quad \ldots$ & $\begin{array}{l}\mathbf{0} \\
1\end{array}$ & 1 & 二 & $\overline{1}$ & $\overline{-}$ & $\overline{-}$ \\
\hline Congenital aortic incompetence & 2 & & - & 2 & - & - \\
\hline $\begin{array}{l}\text { Rheumatic mitral incompetence } \\
\text { Non-coronary cardiomyopathy }\end{array}$ & $\begin{array}{l}3 \\
5\end{array}$ & $\frac{1}{2}$ & 二 & $\begin{array}{l}3 \\
5\end{array}$ & $\overline{2}$ & $\overline{-}$ \\
\hline Total & 38 & 27 & 13 & 30 & 2 & 5 \\
\hline
\end{tabular}

The ages of the adult patients found to have heart disease ranged from 17 to 66 years. The lesions discovered are shown in Tables I, IV, and V. Among the adults a large number of elderly people were found to have cardiomegaly, a dilated and tortuous aorta, and radiological appearances of hypertension. These were not recalled for examination, but the findings were reported to their general practitioners. The actual incidence of cardiac disease discovered by $x$-ray examination in the adult population is therefore higher than the figures given here.

The rate of detection of all forms of heart disease in the available population was 1.62 per thousand and that of congenital heart disease 0.5 per thousand. In different areas with 
populations ranging from 3,000 to 25,000 the rate of detection of acquired valvular and congenital heart disease in the adult population remained remarkably constant around 1.5 per thousand $x$-rayed.

TABLE IV.-Adults-Congenital Heart Disease. (Number of Adults

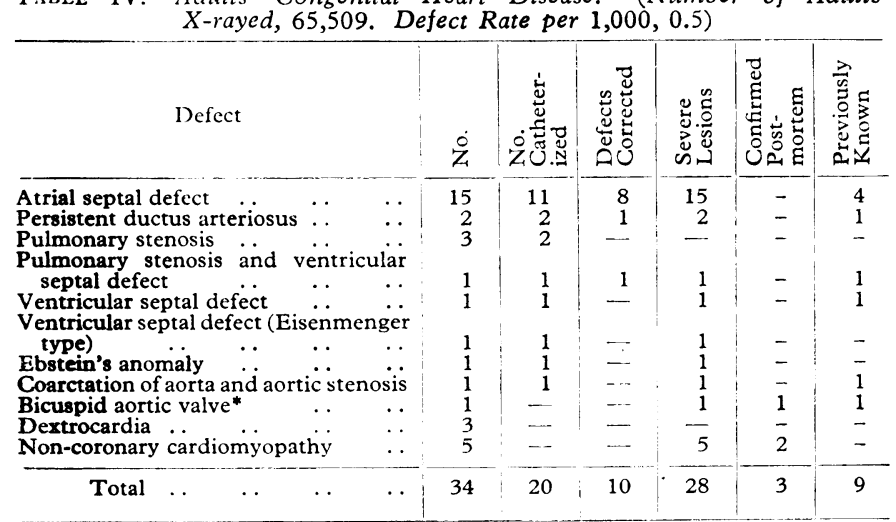

- Death was due to carcinoma of cervix.

TABLE V.-Adults-Acquired Heart Disease. (Number of Adults

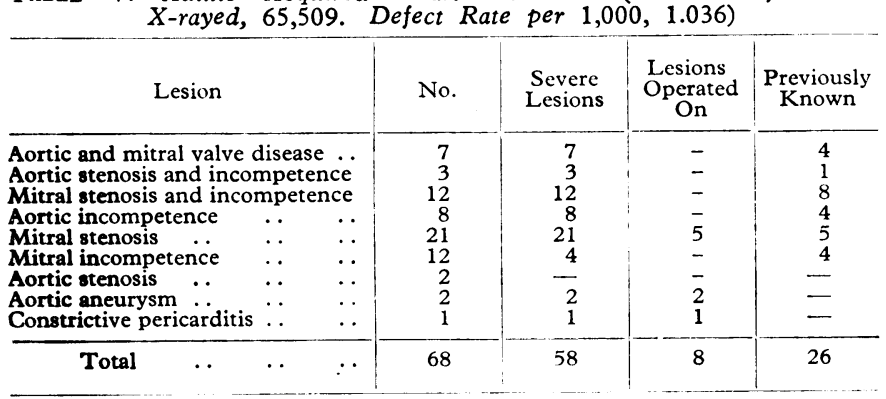

The number of recalls was at first high. This was due to lack of experience and appreciation of the effect of minor skeletal deformities on the cardiac outline. It was also not understood at the beginning of the exercise that the $70-\mathrm{mm}$. camera itself produced a distortion of the cardiac outline. This distortion was also noted by Porte (1952). It is due to the cone-lens-corrected concentric mirror system used in the camera. Any enlargement of the heart chambers or of the great vessels was exaggerated by these techniques. Once these factors were appreciated the proportion of normal recalls was considerably reduced. In the beginning $20-30 \%$ of recalls were discovered to have heart disease, while towards the end of this exercise it had risen to $75 \%$. In the 140 children recalled cardiac murmurs were found in 124 .

\section{Discussion}

Experience gained in this survey has brought out several points which influence the degree of success. The physician scrutinizing the $x$-ray films should have a sound basic knowledge of clinical cardiology and be able to integrate this with the radiological findings. It is helpful if he sees the recalled cases in the first instance and is in close contact with them at all stages of their assessment. Only then can he learn from his successes and failures. With this experience the number of unnecessary recalls falls rapidly. Some anxiety is inevitably caused by the mere fact of recall, so that it is essential to avoid recalling patients without good cause.

Relatively minor variations in chest shape were a frequent reason for the recall of people with normal hearts. Often this could not be determined until the patient was examined, though in some cases the slope of the ribs gave a clue. The characteristic appearance is one of general cardiac enlargement and rather prominent hilar vascular shadows, giving a superficial appearance of atrial septal defect. This may be caused by a flat anterior chest wall and a straight thoracic spine considerably reducing the antero-posterior diameter of the chest or by a minor degree of pectus excavatum. All these patients have innocent pulmonary systolic murmurs. The assessment of an innocent systolic murmur needs very careful clinical judgment, and this is well brought out by Leatham et al. (1963).

In certain conditions, such as atrial septal defect, coarctation of the aorta, persistent ductus arteriosus, some forms of total anomalous pulmonary venous drainage, and Eisenmenger's situation, the cardiac outline is diagnostic. It is not always appreciated that an atrial septal defect with a pulmonary-tosystemic blood-flow ratio of less than $2.5: 1$ can occur with no definite plethora in the lung fields. Another point which should be noted is that the right lung is often more plethoric than the left in atrial septal defect (Fleming, 1959).

Because of its diagnostic $x$-ray appearance atrial septal defect is the commonest congenital heart lesion detected in this type of survey. Indeed, because its clinical diagnosis depends on subtle signs, such as the behaviour of the splitting of the second heart sound, it is often missed until an $x$-ray film is taken.

One of the encouraging results of this exercise was the fact that it alerted the general practitioners in the area to the possibility of undiagnosed heart disease being present in their patients. As a result a number of previously unknown cases of heart disease were discovered. Also cases which had been assessed many years ago were rediscovered and given the benefit of more modern assessment and treatment.

In an exercise of this nature all efforts must be made to prevent the development of a cardiac neurosis. The time interval between recall, presumed diagnosis, and final diagnosis by a cardiologist must be as short as possible. This necessitates a close liaison with a cardiac unit capable of dealing with these problems. Of necessity, the cases occur in batches, and the cardiac unit should be of such a size as to be able to deal with the numbers in as short a period as possible. We were able to achieve success in this direction during our exercise.

The response of the general public and their medical practitioners was surprisingly good. The main theme expressed by the general public was one of gratitude that their lesions were discovered, particularly when we were able to offer surgical correction. Out of all the cases discovered and needing further investigation and treatment there were only two refusals to co-operate. This is contrary to the experience of Morton et al. (1959a, 1959b) in America. In quoting their own experience and that of other similar surveys, they mention that only half of the discovered cases eventually had the necessary investigations or surgical or prophylactic treatment offered to them. The difference in response in this country would appear to be due to two main causes. The first is the provision of free treatment, and the second is the faith of the general public in the benefits of the National Health Service.

There are many mass miniature radiography units active in the detection of chest diseases. It would seem to be a loss of opportunity if the detection of heart disease were not attempted at the same time. The organization required is not complicated and it needs only a liaison with a cardiac unit to make the exercise worth while.

It should be mentioned that this method of discovering unknown heart disease has limitations. A negative finding is no guarantee of the absence of heart disease. Nevertheless this method of detecting heart disease is worth while when combined with a survey for the detection of chest diseases.

\section{Summary}

In the course of an $x$-ray survey of East Suffolk 65,509 adults and 17,620 children had $70-\mathrm{mm}$. chest $x$-ray films taken.

From the population $x$-rayed, 347 adults and 140 children were recalled for cardiological examination, and 71 cases of 
acquired valvular heart disease, 59 cases of congenital heart disease, and 10 cases of non-coronary cardiomyopathy were discovered. In addition, 58 cases of other forms of heart disease were found.

The value, difficulties encountered, and limitations of this method of detecting heart disease are discussed. The factors necessary for success in an exercise of this type are mentioned.

From the experience gained in this survey it is thought worth while to attempt the detection of heart disease in combination with a survey for the discovery of chest diseases.

We are indebted to the general practitioners of East Suffolk for their help and co-operation in this survey and to the administrative staff of the East Suffolk Community $X$-ray Survey Unit for their help in carrying it out ; to Miss J. L. Bond for clerical and secretarial help ; to Dr. S. T. Gray, M.O.H. for East Suffolk, for his support and co-operation; to Dr. A. Gee, Chief School Medical Officer, Lowestoft, for his help and co-operation in the Lowestoft area : to Dr. J. B. Ewen, Senior Administrative Medical Officer, East Anglian Regional Hospital Board, for his help and support during the survey ; to Dr. C. J. Stewart, consultant chest physician, Ipswich Chest Clinic, for providing the facilities and for his generous support of the project ; to Dr. W. A. Oliver, physician, Norfolk and Norwich Hospital, for investigating the cases in the Lowestoft area ; and to Mr. B. B. Milstein, thoracic surgeon to East Anglian Regional Hospital Board and Addenbrooke's Hospital, Cambridge, for operating on the majority of the cases needing surgical treatment and for his help in the preparation of this paper.

\section{REFERENCES}

Adrian Committee (1959). Radiological Hazards to Patients. Interim Report of Committee. H.M.S.O., London.

Bostock, M. I. and Morris, W. (1952). Cand. med. Ass. F., 66, 126.

Flancher, L. H. (1948). Amer. Rev. Tuberc., 57, 375.

Fleming, H A (1959). Circulation, 19, 856.

Heather, A Segal B., 25, 451.

Maclean, A., and Rogen, A (1949). Ibid., 11, 264.

Mathisen, A. K., Mogris, W., and Wilson, G. B. (1950). Amer. Heart F. 39, 505 .

Miller, R. A., Smith, J., Stamler, J., Hahneman, B., Paul, M. H., Abrams, I., Hait, G., Edelman, J., Willard, J., and Stevens, W. (1962). Circulation, 25, 85.

Morton, W., Beaver, M. E. N., and Arnold, R. C. (1959a). F. Amer. med. Ass., 169, 1163

Ass., 169, 1163. . Cleere, R. L., and Dodge, H. J. (1959b). Ibid. $169,1169$.

Porte, D. (1952). Ann. intern. Med., 36, 603.

Porte, D. (1952). Ann. intern. Med., 36, 603.

Schwartz, B., and Berman, B. (1952). A. A. Amer. T. (1951). Amer. Heart \%., 42,355 .

Smith, J. M., Miller, R. A., Marienfeld, C., Hahneman, B., and Willard, J.' (1959). Circulation, 20, 887

West, H. F. (1946). Amer. Rev. Tuberc., 54, 465.

\title{
Oral Respiratory Stimulants in Chronic Respiratory Failure
}

\section{Double-blind Controlled Trial of Amiphenazole and Dichlorphenamide}

\author{
W. MCC. NELSON,* M.в., в.CH., в.A.o. ; WILlIAM F. M. WALLACE,* M.B., в.CH., B.SC., B.A.o.
}

The long-term treatment of chronic bronchitis is very unsatisfactory. Although many drugs are used in this condition, it is not usually possible to halt the steady progression of the disease. A recent development has been the widespread promotion of oral respiratory stimulants for use in chronic bronchitis, despite the fact that there is little evidence that they are of value in this condition (Scadding, 1963).

In the assessment of a drug used in chronic bronchitis, a disease which undergoes marked spontaneous variations from time to time, a double-blind controlled trial is essential. However, most of the reports concerning the use of oral respiratory stimulants have been of uncontrolled trials.

This paper reports a double-blind controlled trial of two commonly used respiratory stimulants in patients with chronic respiratory failure. Both objective and subjective assessments have been made, and side-effects have been recorded. Since objective evidence of respiratory failure must be present before improvement may be objectively assessed, only patients with carbon dioxide retention or reduced arterial oxygen saturation were admitted to the trial.

\section{Plan of Trial and Methods Used}

The two commonly used oral respiratory stimulants, amiphenazole (Daptazole) and dichlorphenamide (Daranide, Oratrol), were chosen for assessment. Active and placebo tablets were identical in appearance, and their identity was unknown to the patients and to the assessors during the trial.

\footnotetext{
* Department of Therapeutics and Pharmacology, the Queen's University
} of Belfast.
Four tablets a day were taken, the total daily dose of amiphenazole being $400 \mathrm{mg}$., and of dichlorphenamide $200 \mathrm{mg}$. These are the standard doses recommended by the manufacturers.

Each patient took the two active drugs and the placebo in three consecutive fortnights, the order of the drugs being varicd so that all possible sequences were equally represented. Assessments were made at the end of each fortnight of treatment, all observations on the same patient being made by the same observer.

The patients chosen for the trial had severe chronic bronchitis and were all disabled but ambulant. They attended as outpatients. All had objective signs of respiratory failure when in a steady state, with either an arterial oxygen saturation of less than $90 \%$ or a mixed venous carbon dioxide tension $\left(\mathrm{PCO}_{2}\right)$ of $53 \mathrm{~mm}$. Hg or more.

Nineteen patients began the trial, but only 12 were included in the final analysis. In one patient results were not obtained owing to illness of the observer. Three others discontinued treatment because of side-effects. The remaining three complained of side-effects, but in addition developed intercurrent illness. Two of them had exacerbations of their chronic bronchitis, and the third developed congestive heart failure, was admitted to hospital, and died with a myocardial infarction.

Of the 12 patients finally included in the trial, 10 were men and two were women. Their ages ranged from 40 to 66 , and averaged 52 years.

Arterial oxygen saturation was measured by ear oxymetry with an Atlas Universal Oxymeter. Hyperaemia of the ear was induced with a cream containing as active ingredients nonylic 